\title{
Endogenous Product Turnover and Macroeconomic
}

\author{
Dynamics*
}

\author{
Masashige Hamano \\ Waseda University
}

\author{
Francesco Zanetti \\ University of Oxford
}

June 29, 2017

\begin{abstract}
This paper introduces endogenous product entry and exit based on creation and destruction of product variety in a general equilibrium model. Recessionary technology shocks induce exit of unprofitable products on impact, allocating resources towards more productive production lines. However, during the recovery phase, less productive production lines survive destruction, counteracting the original increase in productivity. The analysis shows that recoveries hinge on lower product destruction rather than higher product creation. We find that product heterogeneity and the persistence of technology shocks play a critical role for the cyclicality of product turnover. Endogenous product destruction is important to evaluate the effect of permanent policies of entry deregulation and subsidies aimed to stimulate the economy.
\end{abstract}

Keywords: Product heterogeneity, endogenous product destruction, business cycles.

JEL: D24, E23, E32, L11, L60.

\footnotetext{
${ }^{*}$ We would like to thank the Coordinating Editor (Matthias Doepke), an anonymous Associate Editor, two anonymous referees, Almut Balleer, Andrea Colciago, Andreas Irmen, Philippe Martin, Pierre M. Picard and Jacques-Francois Thisse for providing comments and discussions. We thank seminar participants at the 10th joint CEPR/ECB Labour Market Workshop, the University of Luxembourg, the University of Oxford, the EEA/ESEM meetings, the Midwest Macroeconomics meetings, the Annual Conference of the Royal Economic Society and the 2016 Asian Meeting of the Econometric Society for suggestions. The present project was partially supported by the National Research Fund, Luxembourg, the Marie Curie Actions of the European Commission (FP7-COFUND), the Zengin Foundation, the Grant-in-Aid for Young Scientists B (JSPS 15K17027) and the John Fell Oxford University Press Research Fund. All remaining errors are our own. Please address correspondence to: Masashige Hamano, Waseda University, School of Political Science and Economics, 1-6-1 Nishiwaseda Shinjuku-ku, Tokyo 169-8050, JP, email: masashige.hamano@waseda.jp; or Francesco Zanetti, University of Oxford, Department of Economics, Manor Road, Oxford, OX1 3UQ, UK, email: francesco.zanetti@economics.ox.ac.uk.
} 


\section{Introduction}

The importance of product creation and destruction as determinants of market performance is well recognized. ${ }^{1}$ Recent research uses general equilibrium models to investigate the relevance of both margins of adjustment and show that either they play little role for business cycle fluctuations or product creation is the dominant margin of adjustment, thereby suggesting that a constant product destruction is a plausible modelling assumption. $^{2}$ This paper revisits the importance of product destruction for macroeconomic dynamics, and it shows that product destruction is critical to generate realistic fluctuations in product turnover.

Our research is motivated by the observation that high product turnover is a robust stylized fact in the data. Broda and Weinstein (2010), using micro-level data collected at the household level for a six-year period (1994 and 1999-2003), show that product creation is strongly pro-cyclical while product destruction is mildly counter-cyclical. As a result, net product creation (i.e. creation less destruction) is pro-cyclical. ${ }^{3}$ Our paper shows that endogenous product destruction is critical to replicate these stylized facts.

This paper sets up a general equilibrium model that includes endogenous product destruction and creation and nests several tractable specifications as a special case. The baseline model embeds endogenous product destruction by introducing product-specific heterogeneity, imposing that unprofitable production lines stay idle until a positive shock makes them profitable. The model is calibrated to replicate the business cycle statistics on product dynamics in Broda and Weinstein (2010). The mechanism that generates endogenous product destruction is similar to the mechanism used in the trade literature by Melitz (2003) to generate exit dynamics in domestic and export markets. ${ }^{4}$ In particular,

\footnotetext{
${ }^{1}$ See Broda and Weinstein (2010) and references therein.

${ }^{2}$ See Ghironi and Melitz (2005) and Bilbiie et al. (2012) and references therein for a recent discussion of the issue.

${ }^{3}$ The statistics on net product creation, product creation and product destruction are taken from Broda and Weinstein (2010), and they are computed from the ACNielsen Homescan database. According to their estimates, a one percentage point increase in consumption growth is associated with a rise in product creation of 0.299 percentage points and a decrease in product destruction of -0.053 percentage points, respectively. A one percentage point increase in consumption growth is associated with a rise in net creation of 0.351 percentage points. See also Table 3 in section 4.2 .

${ }^{4}$ Ghironi and Melitz (2005) set up a model with endogenous change of exporting state based on
} 
we assume that production lines have different productivity levels and face a common operational cost. Following an aggregate technology shock, production lines that are unable to afford fixed operational costs shut down and stay idle until a new technological improvement makes them profitable, making product destruction an additional margin of adjustment over the business cycle. Product creation is based on sunk entry costs faced by new production lines that limit the number of newly created products, as in Bilbiie et al. (2012). ${ }^{5}$ Finally, we extend the theoretical framework to study the effect of permanent entry deregulation and subsidies to production on the creation and destruction of products and macroeconomic dynamics.

The analysis establishes three main results. First, endogenous product destruction generates two competing effects on the allocation of resources. On impact, a recessionary technology shock eliminates less efficient production lines since it requires producers to have a higher plant-specific productivity level to retain profitability. The impact effect of a recession is to allocate resources toward more efficient products. However, in the aftermath of the shock, aggregate productivity recovers, requiring a lower level of plantspecific productivity to maintain profitable products. During the recovery phase, even less productive production lines are retained in the economy, and this effect counteracts the initial plant-specific productivity increase in the outset of recessions. The analysis shows that recoveries primarily are driven by a decrease in the destruction of unprofitable products rather than an increase in the creation of new products. In the aftermath of a recessionary shock, during the recovery phase, product creation steadily increases, returning to its original pre-recession level whereas product destruction declines at lower levels than its pre-recession level, therefore substantially contributing to the increase in the number of products. ${ }^{6}$

heterogeneous productivity. However, the total number of domestic firms that are forced to exit is exogenously determined.

${ }^{5}$ Hamano and Zanetti (2015) provides an extension of the model that accounts for selective entry by assuming that product creation also depends on plant-specific productivity levels. Newly created products must therefore have sufficiently high productivity levels to remain in the market. This alternative version of the model is able to study the effect of plant-specific characteristics of newly created products on aggregate fluctuations.

${ }^{6}$ Caballero and Hammour (2005) document a similar empirical pattern that they call "reversed liquidationist view." 
Second, we show that product heterogeneity and the degree of persistence of the aggregate productivity shock plays a critical role for the cyclicality of product destruction. In the presence of products with different productivity levels, a substantial adjustment takes place in the cutoff level of productivity, generating a strong counter-cyclical pattern of product destruction. Likewise, in the presence of high productivity persistence, sales decline considerably as a result of consumption-smoothing preferences of households, generating a strong counter-cyclical pattern of product destruction. Therefore, the model generates pro-cyclical product destruction for a relatively low degree of product heterogeneity and persistence in the aggregate productivity shock whereas it generates a-cyclical product destruction for a high degree of product heterogeneity and persistence in the shock. As we discuss below, these mechanisms help reconcile contrasting results on the cyclicality of product destruction in the literature. We show that the degree of product heterogeneity and the persistence of the technology shock are tightly linked to the "insulation effect" of product creation on product destruction, argued in Caballero and Hammour (1994). Specifically, we characterize the dynamic aspects of the insulation effect, which show that a reduction in current product creation insulates future product destruction.

Third, we show that allowing for endogenous product destruction is critical to evaluate the effect of permanent policies targeted to stimulate the economy (i.e. from deregulation to entry costs and subsidies to operational costs). In the presence of exogenous product destruction, market deregulation implemented with a permanent reduction in entry costs generates "sclerosis" (i.e. the survival of production units that would fail to survive in an efficient equilibrium) and leads to a lower product-specific output in the long run. ${ }^{7}$ A fall in entry costs stimulates product creation. However, if product destruction is constant, the number of products in the economy increases, pushing prices upwards and suppressing long-run profits and output. By contrast, in the presence of endogenous product destruction, higher product entry requires higher plant-specific productivity levels to make a product profitable, decreasing marginal costs and increasing long-run profits

\footnotetext{
${ }^{7}$ The term "sclerosis" was coined by Caballero and Hammour (2005).
} 
and output. Similarly, economic policies that permanently decrease operational costs have no effect on the economy if the product destruction rate is constant. However, in the presence of endogenous product destruction, a decrease in operational costs enables less productive products to stay in the market, thereby reducing the long-run, plant-specific productivity and contributing to the creation of "zombie" industry in the economy.

A number of studies investigate the interplay between firm flows and business cycle dynamics. Recent research by Chatterjee and Cooper (2014), Bilbiie et al. (2012), Jaimovich and Floetotto (2008), Lewis and Poilly (2012) and Minniti and Turino (2013) show that the interplay between endogenous firm entry and the variation in the degree of competition generates a strong propagation of shocks in general equilibrium models. Although these studies allow for endogenous firm creation, they assume constant firm destruction. Other studies consider the effect of entry deregulation and subsidies in the presence of endogenous firm destruction. Melitz (2003) investigates the effect of subsidies to entry and fixed costs of production on the stationary equilibrium of an open economy model. Felbermayr and Prat (2011) develop a search model with heterogeneous, multiple worker firms and investigate the long-run effect of sunk entry costs and fixed costs on unemployment. We extend the analysis of these studies by considering a dynamic model.

We also relate to the literature on the relevance of firm heterogeneity for aggregate fluctuations, as established in Gabaix (2011). Ottaviano (2011) introduces firm heterogeneity and endogenous markup using a linear quadratic demand function into a standard two-sector model. The analysis is similar to ours as it allows the interaction between the demand and supply side of the economy. The focus of the aforementioned study is, however, on firm heterogeneity and the implication on the propagation mechanism of technology shock. We instead investigate the interplay between entry and exit under different types of policy shocks. Samaniego (2008) investigates the relevance of establishment entry and exit over the business cycle and finds that establishment dynamics play a limited role on aggregate fluctuations. Lee and Mukoyama (2015), Caunedo (2011), Clementi and Palazzo (2016) and Rossi (2015) undertake a related analysis and assume that establishment destruction is controlled by stochastic operating costs that determine 
the profitability of establishments. They find that establishment creation is important for macroeconomic dynamics. ${ }^{8}$ These studies investigate the relevance of endogenous establishment creation and destruction whereas we focus on the importance of product turnover for aggregate fluctuations. Compared to these studies, the creation and destruction of product variety directly contribute to the consumer's utility. We therefore model explicitly the household consumption and investment decisions, which turn out to have important general equilibrium effects.

Finally, our analysis relates to the realm of research that develops general equilibrium models with endogenous firm creation to investigate the effect of policy reforms on aggregate fluctuations (Shao and Silos (2013), Cacciatore and Fiori (2016) and Cacciatore et al. (2015)) and to study optimal monetary policy (Lewis (2013) and Cacciatore et al. (2016)) and fiscal policy (Chugh and Ghironi (2015) and Colciago (2016)). Compared to these studies, we include endogenous product destruction and focus on its effect for aggregate dynamics.

The remainder of the paper is as follows. Section 2 presents the baseline model with endogenous product creation and destruction. Section 3 discusses the extensions of the model with exogenous product destruction. Section 4 discusses the calibration of the model and reports the results. Section 5 performs sensitivity analysis. Section 6 concludes.

\section{The Model}

The model embeds product creation and product variety diversification and it accounts for endogenous product destruction. The economy is populated by one unit mass of atomistic households that gain utility from consuming goods of different product variety. There is a large firm that has multiple product lines. Upon release, each product draws a specific productivity level from a given distribution and is subject to sunk entry costs. During each period, fixed operational costs are required to maintain production. Both sunk entry costs and fixed operational costs are paid in terms of effective labor, and products that

\footnotetext{
${ }^{8}$ These latest works extend the analysis of earlier studies by Hopenhayn (1992a, 1992b), Hopenhayn and Rogerson (1993) and Campbell (1998).
} 
cannot afford fixed operational costs become unprofitable and stay "idle" until a positive technology shock makes they profitable again. At that point, the product line resumes production.

\subsection{Households}

During each period $t$, the representative household maximizes the expected utility

$$
E_{t} \sum_{i=t}^{\infty} \beta^{i-t}\left(\ln C_{t}-\chi \frac{L_{t}^{1+\frac{1}{\varphi}}}{1+\frac{1}{\varphi}}\right)
$$

where $C_{t}$ is consumption, $L_{t}$ is labor supply, $0<\beta<1$ is the discount factor, $\chi>0$ is the degree of disutility in supplying labor and $\varphi$ is the Frisch elasticity of labor supply. ${ }^{9}$

Consumption is defined over a continuum of goods, $\Omega$, and during each period $t$, only a subset of goods, $\Omega_{t} \subset \Omega$, is available. Each produced good has a unique variety indexed by $\omega \in \Omega_{t}$. The consumption aggregator is

$$
C_{t}=\left(\int_{\omega \in \Omega_{t}} c_{t}(\omega)^{1-\frac{1}{\sigma}} d \omega\right)^{\frac{1}{1-\frac{1}{\sigma}}}
$$

where $c_{t}(\omega)$ is individual demand for variety $\omega$. In particular, $\sigma>1$ is the elasticity of substitution among varieties. The price index that minimizes the consumption expenditure is

$$
P_{t}=\left(\int_{\omega \in \Omega_{t}} p_{t}^{1-\sigma}(\omega) d \omega\right)^{\frac{1}{1-\sigma}},
$$

where $p_{t}(\omega)$ is the individual price of variety $\omega$. Equation (3) is consistent with a welfarebasis index and shows that for a given variety $\omega$, the price index rises (decreases) when the number of available varieties decreases (rises).

The demand for each variety, $\omega$, is

$$
c_{t}(\omega)=\left(\frac{p_{t}(\omega)}{P_{t}}\right)^{-\sigma} C_{t}
$$

\footnotetext{
${ }^{9}$ With $\varphi=\infty$, the marginal disutility of supplying labor becomes constant, $\chi$. When $\varphi=0$, the marginal disutility becomes infinite and the labor supply inelastic.
} 
where $p_{t}(\omega)$ denotes the physical unit price of variety $\omega$.

\subsection{Production, pricing and producing decision}

Products are indexed by their specific productivity, z. Production requires a fixed operational cost of $f_{t}$ units of labor in each period. During each period $t$, the labor demand, $l_{t}(z)$, depends on the scale of effective production, $y_{t}(z) / A_{t} z$. Fixed operational costs are defined in terms of effective labor, $f_{t} / A_{t}$, so that the total labor demand is ${ }^{10}$

$$
l_{t}(z)=\frac{y_{t}(z)}{A_{t} z}+\frac{f_{t}}{A_{t}} .
$$

Fixed costs fluctuate with aggregate labor productivity level, $A_{t}$, and the exogenous term, $f_{t}$, proxies (de)regulation in production.

In each period, a number of new products, $H_{t}$, enters the market. Prior to entry, these new products are identical and producers face a sunk entry cost of $f_{E, t}$ effective labor units. Entry cost is therefore equal to $w_{t} f_{E, t} / A_{t}$ units of consumption goods, where $w_{t}$ is the real wage. Upon entry, each product draws a productivity level, $z$, from a distribution, $G(z)$, with support on $\left[z_{\min }, \infty\right) \cdot{ }^{11}$

Due to fixed operational costs, only a subset of products with a productivity level, $z$, that is higher than the cutoff level, $z_{s, t}$, charges sufficiently lower prices and earns profits, despite the existence of fixed operational cost, $f_{t}$. Destruction of the production unit is therefore endogenous and depends on the cutoff productivity level. In addition to the endogenous destruction, an exogenous depreciation shock, which takes place with probability $\delta \in(0,1)$, hits producers in each period. The shock is independent from

\footnotetext{
${ }^{10}$ To maintain the theoretical framework as close as possible to the benchmark model of Bilbiie et al. (2012), we refrain from embedding physical capital in the model. However, the model accounts for investment decisions in the creation of new products.

${ }^{11}$ Empirical studies by Bloom et al. (2012), Bachmann and Bayer (2013) and Kehrig (2015) show that the distribution of productivity is asymmetric and more spread out in recession. Similarly, Berger and Vavra (2015) and Vavra (2014) show that asymmetries in the responses of economic variables are driven by variations in the dispersion of price changes over the business cycle. Our model is not designed to replicate these important empirical regularities. Instead, it assumes a fixed distribution of productivity, $G(z)$, which allows the cutoff productivity level, $z_{t}$, to change, resulting in different shapes of the distribution of products in the market. Extending the model to incorporate a time-varying productivity distribution would certainly be a very useful extension for future research.
} 
the level of product-specific productivity and materializes at the end of each period. Therefore, $G(z)$ also represents the productivity distribution of all products that have production potential.

Each product faces a residual demand curve with constant elasticity, $\sigma$, described by equation (4), which contributes to the determination of the production scale. Profit maximization of the product prices yields the following optimal pricing decision:

$$
\rho_{t}(z)=\frac{\sigma}{\sigma-1} \frac{w_{t}}{A_{t} z}
$$

which states that the real price of production is a markup over marginal costs. Depending on the level of product-specific productivity, $z$, a product may or may not be produced. Thus, using equation (5) and (6), if production materializes, the real profits are: ${ }^{12}$

$$
d_{t}(z)=\frac{1}{\sigma} \rho_{t}^{1-\sigma}(z) C_{t}-\frac{w_{t} f_{t}}{A_{t}}
$$

Since the elasticity of substitution among varieties is more than unitary $(\sigma>1)$, lower real prices induce a rise in profits.

\subsection{Product average}

To focus on aggregate dynamics across different products, we derive the average product specific productivity across survivors-producers, $\widetilde{z}_{s, t}$. Given the distribution of productivity level, $G(z)$, the mass of products, $N_{t}$, is defined over the productivity levels $\left[z_{\min }\right.$, $\infty)$. Among these products, the fraction $S_{t}=\left[1-G\left(z_{s, t}\right)\right] N_{t}$ of product is produced after surviving product destruction, as described below. Following Melitz (2003) and Ghironi and Melitz (2005), we define the average productivity of surviving products, $\widetilde{z}_{s, t}$, as

$$
\widetilde{z}_{s, t} \equiv\left[\frac{1}{1-G\left(z_{s, t}\right)} \int_{z_{s, t}}^{\infty} z^{\sigma-1} d G(z)\right]^{\frac{1}{\sigma-1}} .
$$

\footnotetext{
${ }^{12}$ As in Chugh and Ghironi (2015), under the assumption of a large firm such as ours, it is possible to internalize the setup entry cost of products in the dividends. The resulting equilibrium conditions, however, are similar.
} 
The term, $\widetilde{z}_{s, t}$ thus contains all the information about the distribution of productivities. Aggregating across productivity levels and substituting equation (8) into equation (6), the average real price of surviving products is

$$
\widetilde{\rho}_{s, t}=\frac{\sigma}{\sigma-1} \frac{w_{t}}{A_{t} \widetilde{z}_{s, t}}
$$

Similarly, average real profits among surviving producers are expressed as follows:

$$
\widetilde{d}_{s, t}=\frac{1}{\sigma} \frac{C_{t}}{S_{t}}-\frac{w_{t} f_{t}}{A_{t}}
$$

Finally, we define average operational profits among total products as $\widetilde{d}_{t}=\left(S_{t} / N_{t}\right) \widetilde{d}_{s, t}$.

\subsection{Product entry and exit}

We assume that products entered at time $t$ only start producing at time $t+1$. These

products are discounted by the stream of their expected profits $\left\{\widetilde{d}_{s, i}\right\}_{i=t+1}^{\infty}$, using the stochastic discount factor of households adjusted by exogenous exit and inducing shock $\delta$. Thus, their expected post entry value is

$$
v_{t}=E_{t} \sum_{i=t+1}^{\infty}[\beta(1-\delta)]^{i-t}\left(\frac{C_{i}}{C_{t}}\right)^{-1} \widetilde{d}_{i},
$$

which represents the share price of equities and mutual funds across different products. Product entry occurs until the expected product value (10) is equal to the entry cost, leading to the free entry condition,

$$
v_{t}=\frac{w_{t} f_{E, t}}{A_{t}}
$$

The timing of entry and of production implies that the number of products evolves according to the law of motion:

$$
N_{t}=(1-\delta)\left(N_{t-1}+H_{t-1}\right)
$$


Among $N_{t}$ number of total product lines, only a subset number of $S_{t}$ products is produced.

For any given specific productivity level, $z$, the producer produces if profits are positive, $d_{t}(z)>0$. Otherwise it terminates production. Inefficient production lines that have drawn a lower productivity level than the cutoff $\left(z \leq z_{s, t}\right)$ necessary to ensure positive profits are discontinued and stay idle until a positive technological process makes them profitable. Endogenous destruction takes place following a "strict productivity ranking," as in Caballero and Hammour (1994, 1996, 2005).

Operational profits become zero for the product with the cutoff productivity level, $z_{s, t}$, provided that the following zero profit cutoff condition holds:

$$
d_{t}\left(z_{s, t}\right)=\frac{1}{\sigma} \rho_{t}\left(z_{s, t}\right)^{1-\sigma} C_{t}-\frac{w_{t} f_{t}}{A_{t}}=0
$$

\subsection{Parametrization of productivity draw}

To solve the model, we must assume a distribution of productivity levels, $z$. We assume the following Pareto distribution for $G(z)$ :

$$
G(z)=1-\left(\frac{z_{\min }}{z}\right)^{\kappa}
$$

where $z_{\min }$ is the minimum productivity level and $\kappa(>\sigma-1)$ determines the shape of the distribution. The parameter $\kappa$ indexes the dispersion of productivity across products. The dispersion decreases as $\kappa$ increases, and the productivity levels are concentrated towards the lower bound $z_{\min }$. When $\kappa=\infty$, all products are located at $z_{\min }$, and products become homogenous. To ensure that variance of the productivity distribution is finite, we assume that $\kappa>\sigma-1$. With this parametrization, we can express the average productivity of surviving products, $\widetilde{z}_{s, t}$, in equation (8) as

$$
\widetilde{z}_{s, t}=z_{s, t}\left[\frac{\kappa}{\kappa-(\sigma-1)}\right]^{\frac{1}{\sigma-1}}
$$

and the fraction of surviving products as 


$$
\frac{S_{t}}{N_{t}}=z_{\min }^{\kappa}\left[\frac{\kappa}{\kappa-(\sigma-1)}\right]^{\frac{k}{\sigma-1}} \widetilde{z}_{s, t}^{-\kappa} .
$$

As mentioned, the product with cutoff productivity level earns zero profits from production, such that $d_{t}\left(z_{s, t}\right)=0$, and productivity levels below the cutoff level $z_{s, t}$ are unprofitable. Substituting equation (14) in the product's real profits (7) yields the equation that determines the cutoff productivity level:

$$
\frac{1}{\sigma} \frac{C_{t}}{S_{t}}=\frac{\kappa}{\kappa-(\sigma-1)} \frac{w_{t} f_{t}}{A_{t}}
$$

\subsection{Household budget constraint and intertemporal problems}

We choose the consumption-based price index, $P_{t}$, as numéraire. The household receives income by supplying labor, $L_{t}$, at the real wage rate, $w_{t}$, by acquiring average dividends

income, $\widetilde{d}_{t}$, and by selling its initial share position, $v_{t}$, of share holdings, $x_{t}$, of the firm composed of existing products, $N_{t}$. The household spends its income on consumption, $C_{t}$, buying $x_{t+1}$ shares of the firm composed of existing products, $N_{t}$, and new products, $H_{t}$, at the share price, $v_{t}$. The household budget constraint is thus

$$
L_{t} w_{t}+x_{t} N_{t}\left(v_{t}+\widetilde{d}_{t}\right)=C_{t}+x_{t+1} v_{t}\left(N_{t}+H_{t}\right)
$$

During each period $t$, the representative household chooses consumption, $C_{t}$, share holding, $x_{t+1}$, and the labor supply, $L_{t}$, to maximize the expected utility function (1) subject to the budget constraint (17). The first-order conditions with respect to consumption and labor supply yield the standard labor supply equation

$$
\chi\left(L_{t}\right)^{\frac{1}{\varphi}}=w_{t} C_{t}^{-1}
$$

The first-order condition with respect to share holdings once combined with the products law of motion (12) and the first-order condition for consumption yields

$$
v_{t}=\beta(1-\delta) E_{t}\left(\frac{C_{t+1}}{C_{t}}\right)^{-1}\left(v_{t+1}+\widetilde{d}_{t+1}\right)
$$


which, once iterated forward, shows that share prices are the expected discounted sum of future dividends.

\subsection{Model equilibrium and solution}

To derive the aggregate equilibrium, we impose labor market clearing. Aggregate labor supply, $L_{t}$, is employed in either the production of consumption goods (intensive margins, i.e. production scale) or the creation of new products (extensive margins):

$$
L_{t}=S_{t} l_{t}\left(\widetilde{z}_{s, t}\right)+H_{t} \frac{v_{t}}{w_{t}}
$$

which can be expressed as ${ }^{13}$

$$
L_{t}=S_{t}\left[(\sigma-1) \frac{\widetilde{d}_{s, t}}{w_{t}}+\sigma \frac{f_{t}}{A_{t}}\right]+H_{t} \frac{v_{t}}{w_{t}}
$$

Equation (19) is equivalent to the aggregated accounting identity of GDP obtained by aggregating budget constraints among households, $Y_{t} \equiv C_{t}+v_{t} H_{t}=L_{t} w_{t}+S_{t} \widetilde{d}_{s, t}$, where $Y_{t}$ is real GDP measured in the welfare basis of expenditures and income. The model consists of 11 equations and 11 endogenous variables among which the number of products, $N_{t}$, is a state variable. Finally, we assume that aggregate productivity follows the law of motion, $\ln \left(A_{t}\right)=\rho \ln \left(A_{t-1}\right)+\varepsilon_{t}$, where $\varepsilon_{t}$ is a normally distributed innovation with zero mean and variance equal to $\sigma_{v}^{2}$. Table 1 summarizes the benchmark model.

The equilibrium conditions do not have an analytical solution. Consequently, we approximate the system by loglinearizing its equations around the stationary steady state. In this way, a linear dynamic system describes the path of the endogenous variables' relative deviations from their steady-state value, accounting for the exogenous shock.

\footnotetext{
${ }^{13}$ Note that $\widetilde{d}_{s, t}=\frac{\widetilde{\rho}_{s, t}}{\sigma} \widetilde{y}_{s . t}-\frac{w_{t} f_{t}}{Z_{t}^{\theta}}$, where $\widetilde{y}_{s, t}$ represents average intensive margins.
} 
Table 1: Summary of the benchmark model

\begin{tabular}{l|l}
\hline Average pricing & $\widetilde{\rho}_{s, t}=\frac{\sigma}{\sigma-1} \frac{w_{t}}{A_{t}} \widetilde{z}_{s, t}$ \\
Real price & $\widetilde{\rho}_{s, t}=S_{t}^{\frac{1}{\sigma-1}}$ \\
Average survivors' profits & $\widetilde{d}_{s, t}=\frac{1}{\sigma} \frac{C_{t}}{S_{t}}-\frac{w_{t} f_{t}}{A_{t}}$ \\
Average profits & $\widetilde{d}_{t}=\frac{S_{t}}{N_{t}} \bar{d}_{s, t}$ \\
Free entry condition & $v_{t}=\frac{w_{t} f_{E, t}}{A_{t}}$ \\
Motion of products & $N_{t+1}=(1-\delta)\left(N_{t}+H_{t}\right)$ \\
Euler equation & $v_{t}=\beta(1-\delta) E_{t}\left(\frac{C_{t+1}}{C_{t}}\right)^{-1}\left(v_{t+1}+\widetilde{d}_{t+1}\right)$ \\
Optimal labor supply & $\chi\left(L_{t}\right)^{\frac{1}{\varphi}}=w_{t} C_{t}^{-1}$ \\
ZCP & $\frac{1}{\sigma} \frac{C_{t}}{S_{t}}=\frac{\kappa}{\kappa-(\sigma-1)} \frac{w_{t} f_{t}}{A_{t}}$ \\
Surviving rate & $\frac{S_{t}}{N_{t}}=z_{\min }^{\kappa}\left[\frac{\kappa}{\kappa-(\sigma-1)}\right]^{\frac{\kappa}{\sigma-1}} \widetilde{z}_{s, t}^{-\kappa}$ \\
Labor market clearing & $L_{t}=S_{t}\left[(\sigma-1) \frac{\widetilde{d}_{s, t}}{w_{t}}+\sigma \frac{f_{t}}{A_{t}}\right]+H_{t} \frac{v_{t}}{w_{t}}$ \\
\hline
\end{tabular}

\section{A model with exogenous destruction}

In this section, we describe the extension to the benchmark model and rule out endogenous destruction. The baseline model nests a model with exogenous product destruction when operational fixed costs are set to zero $\left(f_{t}=0\right)$. In this instance, all products engage in production $\left(N_{t}=S_{t}\right)$, and the plant-specific productivity level becomes irrelevant for the product profitability. From equation (15), the average productivity level of producers remains at its steady state level: $\widetilde{z}_{s, t}=\widetilde{z}_{s}$. Therefore, in the model with exogenous product destruction, equations (15) and (16) are removed from the system.

\section{Results}

In this section, we describe the calibration of the model and investigate how the presence of endogenous product creation and destruction contributes to macroeconomic dynamics. In particular, to isolate the effect of endogenous product destruction, we compare outcomes from the benchmark model against those of the model with exogenous product destruction rate. We perform the analysis by studying the variables' responses to recessionary productivity shocks, permanent product entry deregulation and permanent 
subsidies. We also compare business cycle statistics across the different specifications of the model.

\subsection{Calibration}

\begin{tabular}{rlr}
\multicolumn{3}{c}{ Table 2: Calibration of the model } \\
\hline$\beta$ & Discount factor & 0.99 \\
$\varphi$ & Frisch elasticity of labor supply & 2 \\
$\chi$ & Disutility of supplying labor & 0.9884 \\
$\sigma$ & Elasticity of substitution among varieties & 11.5 \\
$\kappa$ & Distribution parameter & 11.5070 \\
$\delta$ & Exogenous destruction rate & 0.0588 \\
$f$ & Fixed operational costs & 0.0075 \\
$A$ & Steady-state level of aggregate productivity & 1 \\
$z_{\text {min }}$ & Minimum idiosyncratic productivity level & 1 \\
$f_{E}$ & Fixed entry costs & 1 \\
$\rho$ & Persistence of aggregate productivity & 0.979 \\
$\sigma_{v}$ & Standard deviation of productivity shocks & 0.0072 \\
\hline
\end{tabular}

Table 2 provides a summary of the calibration of the benchmark model. We calibrate the model on quarterly frequencies. The value of discount factor, $\beta$, and the Frisch elasticity of labor supply, $\varphi$, are set to 0.99 and 2 , respectively. These values are within the range of those used in the literature. The value of the parameter of the disutility of supplying labor, $\chi$, is set to 0.9884 to deliver a steady-state labor supply equal to one. ${ }^{14}$ The elasticity of substitution among varieties, $\sigma$, is set to 11.5 , within brand elasticity, based on Broda and Weinstein (2010). ${ }^{15}$

We calibrate the parameter, $\kappa$ that determines the shape of the distribution of productspecific productivity to replicate the mean relative sales of exiting products to those of the average products, 0.09, and also the mean quarterly endogenous destruction rate,

\footnotetext{
${ }^{14}$ We set $\chi$ equal to 0.9873 in the model without endogenous destruction. This choice is a mere normalization, with no effect on the system dynamics, as outlined in Bilbiie et al. (2012).

${ }^{15}$ Ghironi and Melitz (2005) set the elasticity of substitution across variety to 3.8, which also corresponds with the elasticity between local and imported goods. As a robustness check, we have simulated the model with alternative lower values (i.e. setting $\sigma=7.5$ to match the across brand elasticity in Broda and Weinstein (2010)). The impulse response functions are qualitatively similar to those in our benchmark calibration. An appendix that details the findings is available on request to the authors.
} 
$0.24 / 4=0.06$, as in Broda and Weinstein (2010). ${ }^{16}$ To achieve this calibration, we set the steady-state value of subsidies, $f$, equals to 0.0075 . The value of $\kappa$ is critical for the dynamic properties of the model. Therefore, we conduct a sensitivity analysis on this parameter in the last section of the paper. For the version of the model with exogenous destruction, operational fixed costs are set equal to zero $(f=0)$.

The exogenous rate of product destruction, $\delta$, is set to match the mean annual product creation rate of 0.25 in Broda and Weinstein (2010), consistent with equation (12) at the steady state. Therefore, we set the exogenous destruction rate, $\delta$, to 0.0588 , implying that, on average, 5.8 percent of products are exogenously destroyed per quarter. We normalize $A, z_{\min }$ and $f_{E}$ to be equal to one. ${ }^{17}$ Appendix A provides the derivation of the steady state for different versions of the model.

Finally, we set the persistence parameter, $\rho$, and the standard deviation of innovations, $\sigma_{v}$, equal to 0.979 and 0.0072 , respectively, as in King and Rebelo (1999). ${ }^{18}$

\subsection{Cyclicality of product turnover}

To investigate how product creation and destruction co-move with economic activity, we compare how changes in consumption growth correlate with movements in product creation, destruction and net creation. As outlined in Ghironi and Melitz (2005) and Bilbiie et al. (2012), we define the data consistent variables by deflating each original variable with the observed level price index, $\widehat{P}_{t}$. Therefore, any real variable $X_{t}$ measured

\footnotetext{
${ }^{16}$ The relative sales of exiting products with respect to the average of all products in our theoretical model is:

$$
\frac{\frac{1}{G\left(z_{s, t}\right)} \int_{z_{\min }}^{z_{s, t}} S_{t}^{\psi(\sigma-1)-1} \rho(z)^{1-\sigma} d G(z)}{\int_{z_{\min }}^{\infty} S_{t}^{\psi(\sigma-1)-1} \rho(z)^{1-\sigma} d G(z)}=\frac{1-z_{s, t}^{-\kappa} z_{s, t}^{\sigma-1}}{1-z_{s, t}^{-\kappa}} .
$$

The corresponding endogeous destruction rate in the theoretical model is $1-S / N$.

${ }^{17}$ To calibrate the product destruction rate, our calibration strategy is to normalize $z_{\min }=1$ and set the steady-state value of fixed operational costs to match the average quarterly product destruction rate in the data. Ghironi and Melitz (2005) use a similar calibration strategy. Hence, $z_{\text {min }}$ plays no role on the level of product destruction whereas $f$ is the parameter that determines the rate of product destruction.

${ }^{18}$ The calibration of the model is aimed to capture the dynamics of the product turnover in Broda and Weinstein (2010), which covers the six-year period 1994 and 1999-2003. The short time span makes the estimation of the innovation parameters $\left(\rho\right.$ and $\left.\sigma_{v}\right)$ unreliable. We therefore resort to standard values in the literature. However, in section 5, we perform extensive robustness analysis on the parameter $\rho$ and show that it plays an important role for product turnover.
} 
in welfare-based CPI, $P_{t}$, is transformed to those $X_{R, t}$ deflated with the empirical-based CPI, $\widehat{P}_{t}$, by the following operation: $X_{R, t} \equiv P_{t} X_{t} / \widehat{P}_{t}$.

The measure of consumption that is consistent with observed data is $C_{R, t}=\widetilde{y}_{s, t} S_{t}$, since it abstracts from the welfare effect imputed to the extensive margin of product variety. Similar to Broda and Weinstein (2010), by combining equations (12) and (15) and loglinearizing the resulting equation around the stationary steady state, we decompose the deviation of the consumption growth rate from its steady state as: ${ }^{19}$

$$
\widehat{C}_{R, t}=\underbrace{\widehat{\widetilde{y}}_{s, t}+\widehat{N}_{t-1}}_{\text {Existing products }}-\underbrace{\left(\kappa \widehat{\widetilde{z}}_{s, t}+\delta \widehat{N}_{t-1}+\frac{\delta^{2}}{1-\delta} \widehat{H}_{t-1}\right)}_{\text {Product destruction }}+\underbrace{\frac{\delta}{1-\delta} \widehat{H}_{t-1}}_{\text {Product creation }},
$$

where each variable is expressed in deviation from its steady-state level. The first two terms $\left(\widehat{\widetilde{y}}_{s, t}+\widehat{N}_{t-1}\right)$ on the right side of equation (20) show that consumption growth depends on changes in average real value of the existing products. The terms in the brackets represent the part of consumption growth that depends on endogenous $\left(\kappa \widehat{\widetilde{z}}_{s, t}\right)$ and exogenous $\left(\delta \widehat{N}_{t-1}+\delta^{2} /(1-\delta) \widehat{H}_{t-1}\right)$ product destruction, in which $\delta^{2} /(1-\delta) \widehat{H}_{t-1}$ captures exogenous destruction of new products. The last term $\left([\delta /(1-\delta)] \widehat{H}_{t-1}\right)$ describes the part of consumption growth related with product creation.

Similar to Broda and Weinstein (2010), in order to quantify the cyclicality of product creation and destruction, we present the patterns of net-product creation (i.e. creation less destruction) as well as product creation and destruction separately. Broda and Weinstein (2010) describe the co-movements of each of these variables by regressing consumption growth on net product creation, product creation and product destruction, respectively. They establish that product creation and net product creation is pro-cyclical whereas product destruction is counter-cyclical in U.S. data. To evaluate the performance of the different models, we produce the regression slope between net product creation, product creation and product destruction and consumption growth for the benchmark model with

\footnotetext{
${ }^{19}$ Using equation (12), the number of products manufactured in time period $t$ is partitioned into two parts as: $N_{t}=\left(N_{t-1}+H_{t-1}\right)-\delta\left(N_{t-1}+H_{t-1}\right)$. The first term, $\left(N_{t-1}+H_{t-1}\right)$, is the number of existing products and new products from the previous period whereas the second term, $\delta\left(N_{t-1}+H_{t-1}\right)$, is the number of existing and entrants that are destructed exogenously. By loglinearizing the first and second term, we obtain equation (20).
} 
endogenous product destruction as well as for the alternative version of the model with exogenous product destruction. We then compare them against the same statistics in the data. ${ }^{20}$ Table 3 reports the results.

Table 3: Regression slopes

\begin{tabular}{l|lll} 
& Net creation & Creation & Destruction \\
\hline U.S. data & 0.351 & 0.299 & -0.053 \\
Benchmark & 0.402 & 0.312 & -0.090 \\
Exogenous destruction & 0.264 & 0.315 & 0.051 \\
\hline
\end{tabular}

Notes: The observed statistics on net product creation, product creation and product destruction are from Broda and Weinstein (2010), which are computed from the ACNielsen Homescan database. Each entry shows the elasticity of a variable with respect to consumption growth.

The benchmark model that embodies endogenous product destruction and the model with exogenous destruction generate pro-cyclical patterns of net product creation with consumption growth (a one percentage point increase in consumption is associated with increase in net creation of 0.402 and 0.264 percentage points, respectively) that are close to the value of 0.351 percentage points in the data. All two models generate pro-cyclical patterns of product creation and consumption growth with the regression slope equal to 0.312 and 0.315 , respectively, which are larger than the value of 0.299 in the data. Only the benchmark model successfully reproduces the counter-cyclical movements in product destruction, generating a regression slope equal to -0.090 , similar to the value in the data. ${ }^{21}$ Instead, the model with exogenous destruction generates pro-cyclical movements in product destruction (i.e., the regression slope equal to 0.051). This latest finding further outlines that the presence of endogenous product destruction is critical to replicate the

\footnotetext{
${ }^{20}$ All series are detrended by HP filter, using a smoothing parameter equal to 1600 . Second moments of the theoretical models are computed by frequency domain techniques. Specifically, the regression slope between a variable $x$ and $y, b_{y, x}$ is computed as

$$
b_{y, x}=\rho_{x y} \frac{S t d(y)}{S t d(x)},
$$

where $\rho_{x y}$ denotes unconditional correlation between $x$ and $y$.

${ }^{21}$ Note that Lee and Mukoyama (2015) report a similar pattern for establishment creation but they detect pro-cyclical establishment destruction using U.S. manufacturing data. We impute the difference to the specific data set used.
} 
counter-cyclicality of product destruction. To gain an intuition on the findings, equation (20) shows that, in the absence of endogenous product destruction (i.e., $\widehat{\widetilde{z}}_{s, t}=0$ ), a fall in newly-introduced and existing products leads to a strong positive co-movement between product destruction and consumption growth. On the contrary, in the presence of endogenous product destruction, the average level of productivity rises, leading to a negative correlation between product destruction and consumption growth, as in the data.

To evaluate the overall performance of the model, we compare the second moments of key macroeconomic variables and their correlation with output. ${ }^{22}$ The data are taken from King and Rebelo (1999), and results are reported in Appendix B. The benchmark model and the alternative version of the model show similar performance in reproducing the observed standard deviations of the aggregate macroeconomic variables of output, consumption and investment. Overall, the analysis shows that the theoretical models replicate relatively well movements in aggregate data. As we have discussed above, however, the model with endogenous product destruction is able to capture the negative correlation between consumption and product destruction whereas the model with exogenous product destruction fails to replicate this important stylized facts. ${ }^{23}$

\subsection{Impulse response functions}

Figures 1-4 present impulse response functions to a one percent recessionary productivity shock, $A_{t}$, a one percent permanent reduction in entry costs, $f_{E, t}$, and a one percent permanent reduction in operational costs, $f_{t}$, respectively. Each entry reports responses for the benchmark economy (solid line) and the economy with exogenous destruction (dashed line).

\footnotetext{
${ }^{22}$ It would be interesting to extend the model to include additional shocks (i.e., demand shocks) to investigate whether they have non-trivial implications for the dynamic properties of product creation and product destruction. We leave this extension open to future research. However, it is worth noting that although the model does not include demand shocks explicitly, product turnover acts as an endogenous demand shock since the agents have preferences for variety. Therefore the model indirectly accounts for movements in demands.

${ }^{23}$ Hamano and Zanetti (2015) shows that results are robust to alternative calibrations of the elasticity of labor supply, $\varphi$, within a model that accounts for different preferences for variety. An appendix that details robustness analysis is available on request.
} 


\subsubsection{Recessionary productivity shock}

Figure 1 shows the response of key variables to a negative productivity shock. On impact, a recessionary technology shock raises fixed operational costs requiring higher productspecific productivity level for the product to survive destruction, increasing the average productivity level of products $\left(\widetilde{z}_{s, t}\right)$. This process generates an increase in the destruction of less efficient products. As a result, surviving products charge lower prices $\left(\widetilde{\rho}_{s, t}\right)$, which dampen the decrease in profits $\left(\widetilde{d}_{s, t}\right)$ and the scale of production $\left(\widetilde{y}_{s, t}\right)$ due to a recessionary shock. The figure shows that when the product destruction is constant, the on-impact fall in prices is contained since product-specific productivity fails to rise in response to the shock, which results in a larger decline both in profits and intensity in production on impact of the shock. Notice that the recession generates a "cleansing" effect on impact, consistent with Caballero and Hammour (1994), since less efficient products are destroyed at the outset of a recession. However, as the recovery phase starts and the adverse shock dissipates, the product-specific productivity level required to retain the product's profitability decreases. As a result, even less productive production lines remain in the economy. Accordingly, destruction is lower compared to the initial steady state along the recovery phase in the benchmark model. This mechanism counteracts the initial cleansing effect of recessions and is absent in the model with exogenous product destruction.

Figure 2 plots cumulative impulse response functions of product creation and destruction associated with a recessionary productivity shock. The cumulative responses compound the effect of the adverse shocks in the contractionary and recovery phases, therefore accounting for the overall effects of the shocks. The recessionary shock induces the cumulative reaction of product creation to increase but remain negative whereas cumulative product destruction increases on impact but then declines in the aftermath of the shock. The sign reversal in the cumulative response of product destruction is due to the lower product-specific productivity required for production lines to remain profitable in the recovery phase, which reduces product destruction. Hence, in the presence of endogenous product destruction, recoveries hinge on lower product destruction rather

than higher product creation. This "reversed-liquidationist" (Caballero and Hammour 
Figure 1: Impulse response functions to a recessionary productivity shock
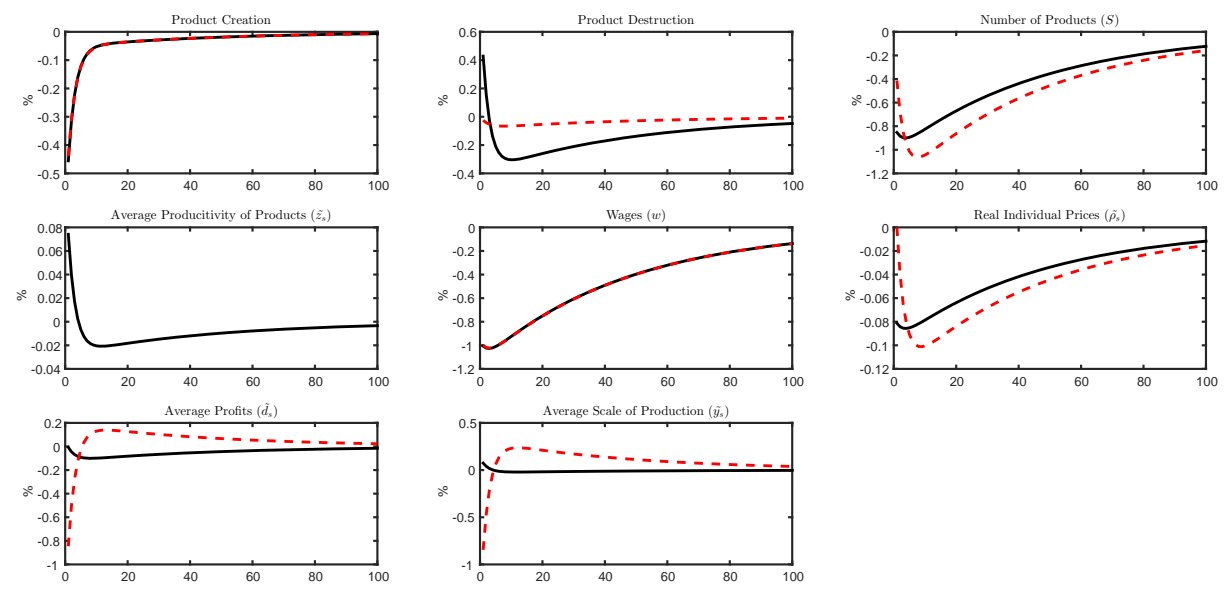

Notes: Each entry shows the percentage-point response of one of the model's variables to a one-percentage deviation of the shock for the benchmark economy (solid line) and the economy with exogenous destruction (dashed line).

2005) pattern is in line with a related strand of literature that focuses on worker flows (Davis et al. (2006) and Caballero and Hammour (2005)) that finds that a fall in worker separation is the primary channel for recovery. ${ }^{24}$

\subsubsection{Permanent entry deregulation}

Figure 3 shows the effect of product entry deregulation, proxied by a permanent onepercent reduction in sunk entry costs $\left(f_{E, t}\right)$. A long-lasting decrease in entry costs induces a permanent rise in the creation of products. The increase in the number of new products raises labor demand and generates a permanent increase in wages $\left(w_{t}\right)$. In the presence of endogenous product destruction, higher wages command higher product-specific productivity to maintain a production line's profitability (i.e. $\widetilde{z}_{s, t}$ rises) and therefore leaves marginal costs $\left(\widetilde{\rho}_{s, t}\right)$ unchanged, along with a rise in the production scale $\left(\widetilde{y}_{s, t}\right)$ and profits

\footnotetext{
${ }^{24}$ To investigate the extent to which higher product destruction is relevant for welfare, it is critical to consider product-quality upgrading, which Aghion and Howitt (1992) establish as a distinguishing feature of newly-created products. Since our model abstracts from quality upgrading, it fails to account for this important channel that surely entails relevant welfare effects. In a recent paper, Hamano and Zanetti (2017) develop a model with quality upgrading and endogenous entry and exit of firms that can be extended to study the welfare effect of a fall in product destruction in the presence of quality upgrading. The investigation of this issue is certainly an interesting extension for future research.
} 
Figure 2: Cumulative impulse response functions to a recessionary productivity shock
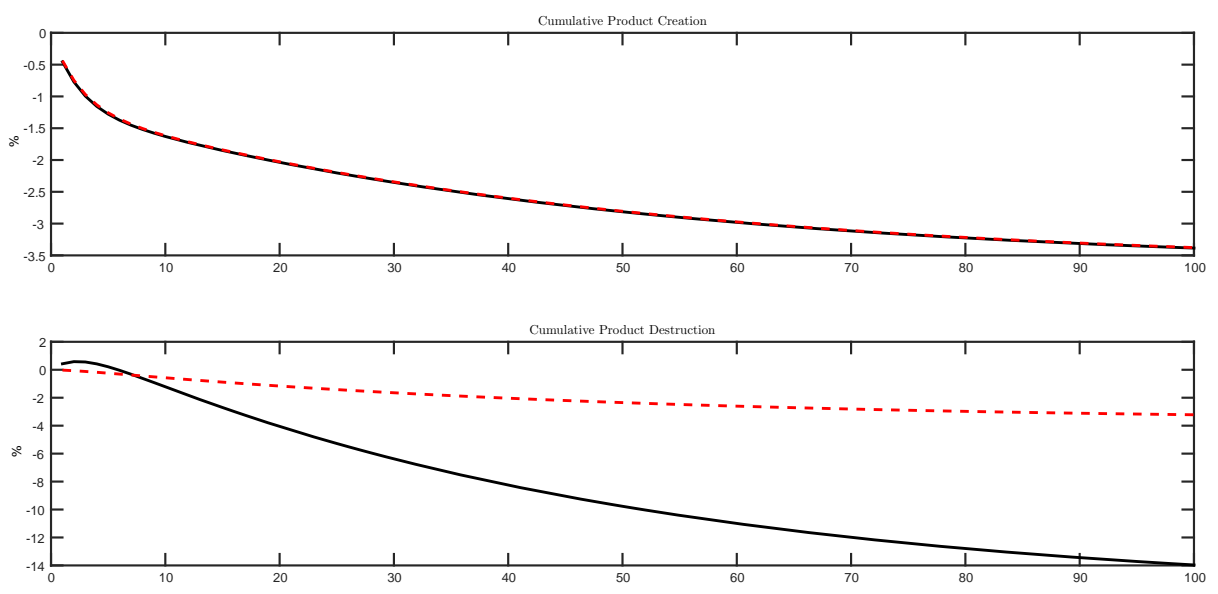

Notes: Each entry shows the cumulative impulses to a percentage-point response of establishment creation and destruction to a one-percentage deviation of the shock for the benchmark economy (solid line) and the economy with exogenous destruction (dashed line).

$\left(\widetilde{d}_{s, t}\right)$.

It is worth noticing that with endogenous product destruction, the effect of deregulation is to permanently increase the average product-specific productivity in the economy. The rise in wages in response to higher product entrance commands permanently higher product-specific productivity levels for the production lines to remain profitable.

The responses of the variables are substantially different when product destruction is constant. In this instance, a raise in wages increases marginal costs (since product productivity remains constant) and therefore induces a fall in each incumbents' scale and profits. This mechanism generates "sclerosis" (i.e. the survival of production units that would not survive in an efficient equilibrium) that echoes the findings on worker flows in Caballero and Hammour (2005). ${ }^{25}$

\footnotetext{
${ }^{25}$ However, in our framework, different from Caballero and Hammour (2005), there is no "scrambling" effect that reduces the effectiveness of the restructuring process related to financial constraints in product creation.
} 
Figure 3: Permanent deregulation shock
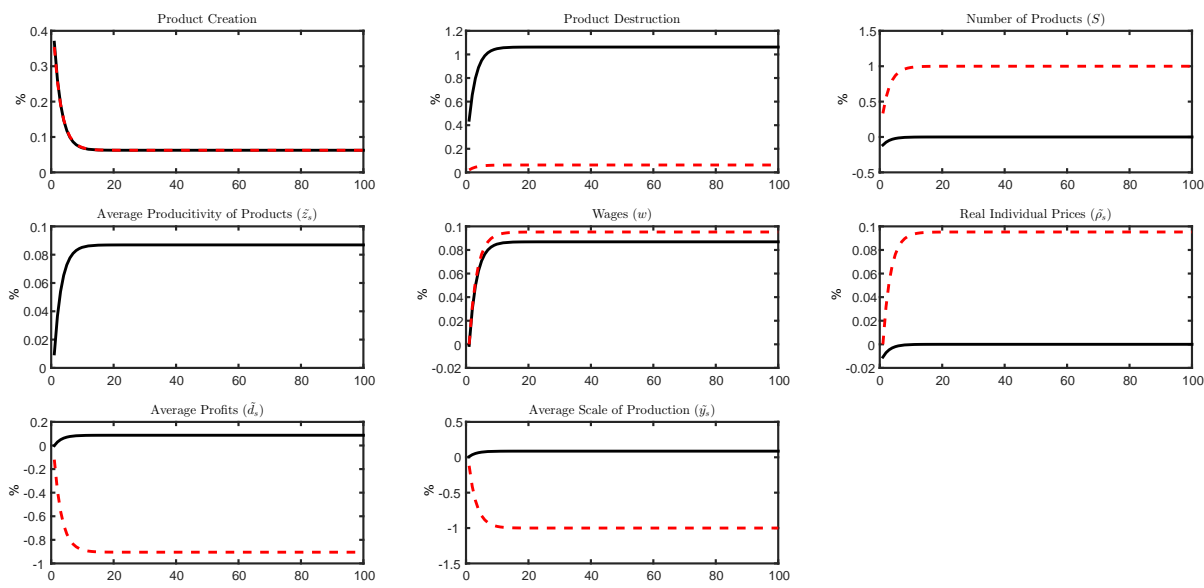

Notes: Each entry shows the percentage-point response of one of the model's variables to a permanent deregulaton shock for the benchmark economy (solid line) and the economy with exogenous destruction (dashed line).

\subsubsection{Permanent subsidy increase}

Figure 4 shows the effect of product subsidies, proxied by a permanent one-percent reduction in fixed operational costs $\left(f_{t}\right)$. By assumption, subsidies are irrelevant for the model with exogenous product destruction (i.e., $f_{t}=0$ ) whereas they play an important role in the model with endogenous product destruction, due to their interplay with the profitability of the production line.

In the benchmark model, a permanent increase in subsidies leaves product creation almost unchanged and induces a permanent fall in product-specific productivity $\left(\widetilde{z}_{s, t}\right)$ that decreases product destruction. As a result, net creation and the number of products $\left(S_{t}\right)$ rises, which in turn increases the labor demand and raises wages $\left(w_{t}\right)$. Consequently, marginal costs $\left(\widetilde{\rho}_{s, t}\right)$ increase, and the production scale $\left(\widetilde{y}_{s, t}\right)$ and profits $\left(\widetilde{d}_{s, t}\right)$ fall.

This analysis shows that a reduction in fixed operational costs generates a permanent decrease in the average product-specific productivity in the economy. However, the propagation channel is different from the case of deregulation, and in this case the results are driven by the increase in profitability due to lower operational costs despite the counteracting effect of increasing wages. These dynamics account for the findings in Caballero 
Figure 4: Permanent subsidy shock
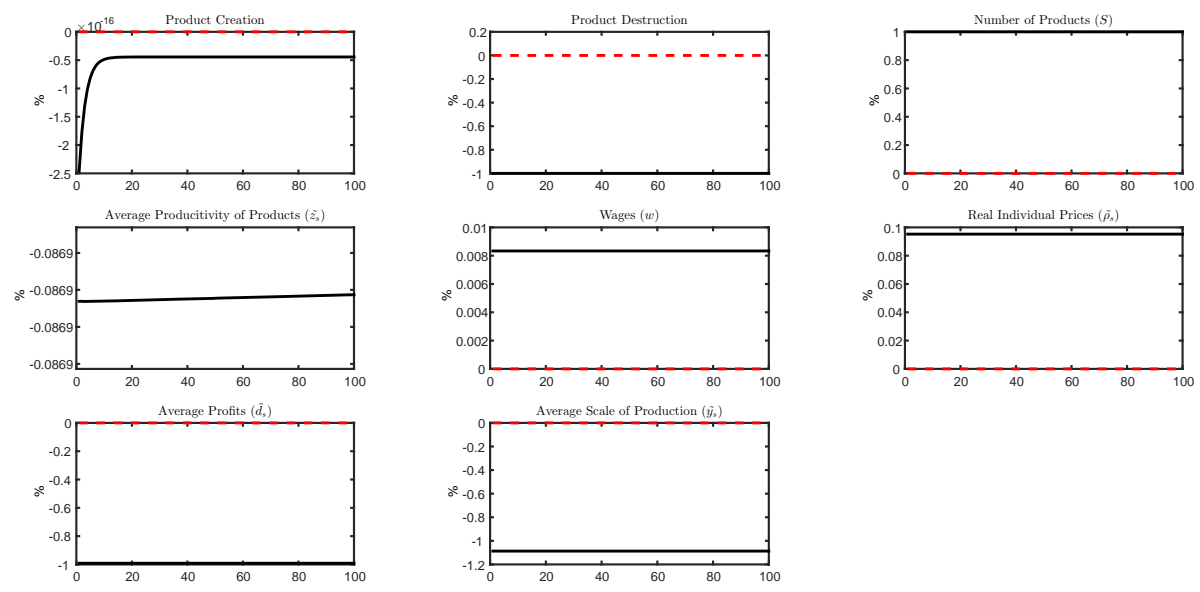

Notes: Each entry shows the percentage-point response of one of the model's variables to a permanent subsidy shock for the benchmark economy (solid line) and the economy with exogenous destruction (dashed line).

et al. (2008), suggesting that the indiscriminate channeling of financial support to firms depressed the long-run restructuring process of the Japanese economy in the aftermath of the early 1990s crisis. ${ }^{26}$

\section{$5 \quad$ Sensitivity analysis}

In this section, we discuss the sensitivity of the cyclical properties of product destruction and creation to the parameter $\kappa$ that determines the degree of product heterogeneity by controlling the shape of the distribution of product-specific productivity, and the technological parameter $\rho$ that determines the degree of persistence of technology shocks. ${ }^{27}$ The analysis is performed using the same calibration of the benchmark model, with the

\footnotetext{
${ }^{26}$ Our results of the entry deregulation and production subsidies are related to the literature on product market reforms and unemployment (see Blanchard and Giavazzi (2003), Zanetti (2009) and the references therein). Felbermayr and Prat (2011), Cacciatore (2014) and Cacciatore et al. (2016) present a novel channel based on firm heterogeneity: entry deregulation or subsidies for incumbents change the cutoffproductivity level and unemployment decreases in the steady state since highly productive firms employ a large number of workers. Our findings are consistent with this result despite the model abstracts from unemployment.

${ }^{27}$ Poschke (2014) and Bonfiglioli et al. (2016) and Bonfiglioli et al. (2017) show that the degree of heterogeneity is an important dimension to consider in the analysis since it varies across countries, sectors and time.
} 
exception of parameter $\kappa$ and $\rho .^{28}$

\subsection{Product destruction and creation}

The left entry of Figure 5 shows the contemporaneous correlation of product destruction with output for different values of parameters $\kappa$ and $\rho$. High values of $\kappa$ lead to a more positive correlation between output and product destruction, for any given value of $\rho$.

Figure 5: Correlation of product destruction and creation with output
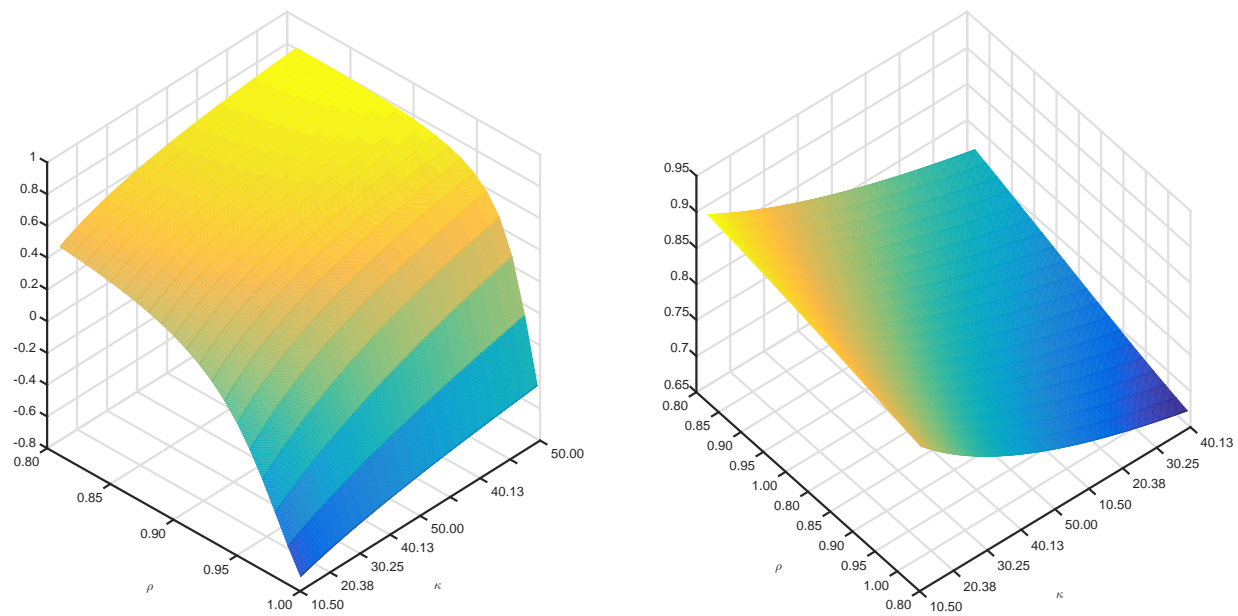

Notes: The left (right) entry shows the contemporaneous correlation of product destruction (creation) with output.

The intuition for this finding is straightforward. Equation (20) shows that consumption growth falls for high values of $\kappa$, generating a negative correlation between product destruction and output. However, as explained in Section 2, high values of $\kappa$ lead to more homogenous products whose productivity levels are clustered at the lower end of the productivity distribution $\left(z_{\min }\right)$. The change in the distribution of productivity dampens the movements in the cutoff level of productivity, $\widehat{\widetilde{z}}_{s, t}$, and therefore reduces the negative effect of the cutoff level of productivity on the correlation between consumption growth

\footnotetext{
${ }^{28}$ We report the cyclical properties of product creation and destruction with an empirically-consistent measure of output. We performed the same robustness analysis using an empirically-consistent measure of consumption for the benchmark model, and we established that results continue to hold. An appendix that details these results is available on request to the authors.
} 
and product destruction. At the limit, when $\kappa=\infty$, all products are located at the lowest end of the product distribution (i.e. $z=z_{\min }=1$ ) and products are perfectly homogenous so that no adjustment takes place in the cutoff level of productivity, $\widehat{\widetilde{z}}_{s, t}$. In this instance, the cutoff level of productivity has no effect on consumption growth, and the correlation between consumption growth and product destruction becomes positive, as shown in equation (20). On the other hand, for small values of $\kappa$, product heterogeneity is large and the cutoff level of productivity, $\widehat{\widetilde{z}}_{s, t}$, adjusts sharply to changes in the economy, leading to strong counter-cyclical movements in product destruction.

The persistence parameter of the technological process, $\rho$, plays an important role for the cyclicality of product destruction. The left entry of Figure 5 shows that when the value of $\rho$ increases, the counter-cyclicality of product destruction rises. When the persistence of the technological process is high, a recessionary shock generates a prolonged fall in wage income as productivity takes longer to return to the original steady-state level in the aftermath of the shock. Since the household prefers smooth consumption over time, current consumption declines substantially in the prospect of a long period of low wage income, generating a sharp rise in product destruction and a reduction in output. The higher the persistence parameter, the stronger the reduction in output and the countercyclicality of product destruction with output.

These findings help to reconcile the contrasting results in Lee and Mukoyama (2015) and Samaniego (2008), whose theoretical models generate pro-cyclical and a-cyclical plant destruction, respectively. In particular, our analysis shows that the cyclical properties of product destruction are tightly linked to the degree of product heterogeneity $(\kappa)$ and the shock persistence $(\rho)$. The model is able to generate pro-cyclical product destruction for a low degree of heterogeneity or a low degree of persistence in the technological process whereas product destruction becomes a-cyclical for specific combinations of product heterogeneity and shock persistence.

The right entry of Figure 5 shows the contemporaneous correlation of product creation with output for different values of parameters $\kappa$ and $\rho$. The contemporaneous correlation of product creation with output is increasing with $\kappa$, for any given level of $\rho$. Following 
a recessionary shock, the sunk entry cost exceeds the value of new product and prevents the creation of new products in equilibrium. Unlike product destruction, product creation remains pro-cyclical, with the correlation ranging between 0.6-0.8 for a wide range of parameter values. Pro-cyclical product creation is generated by the large amount of investments for new product creation at the time of an expansionary productivity shock and is broadly insensitive to different values of parameters $\kappa$ and $\rho$.

To summarize, the sensitivity analysis shows that product heterogeneity plays an important role in the cyclical properties of product creation and destruction, consistent with the realm of research initiated by Gabaix (2011). The analysis also outlines important interactions between product heterogeneity and the persistence of technology shocks: a high shock persistence amplifies the adjustments in product destruction for a given degree of product heterogeneity.

\subsection{The insulation effect}

In this section, we show that changes in $\kappa$ and $\rho$ enable us to revisit the "insulation effect" in Caballero and Hammour (1994), who find that reduced product creation during recessions hampers the adjustment in product destruction. The entries in Figure 6 show the correlation between current product creation and product destruction at nine leads and lags for different values of $\kappa$ (left panel) and $\rho$ (right panel).

Figure 6: Correlation of product creation with leads and lags of product destruction
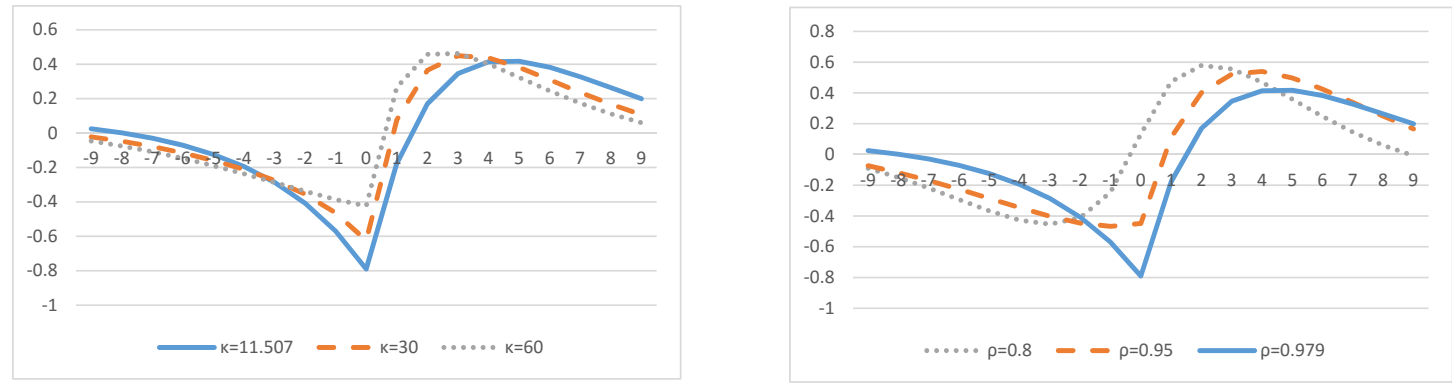

Notes: The left (right) panel shows the correlation of current product creation with leads and lags of product destruction for different values of $\kappa(\rho)$.

The panels show a "s-shaped" pattern of cross-correlations, which is generated by the 
dynamics of product turnover in the model. In the aftermath of a recessionary shock, product creation falls and product destruction rises, generating a negative correlation between current product creation and destruction on impact. ${ }^{29}$ Movements in product creation have two opposing effects on the leads and lags of product destruction. On the one hand, a current fall in product creation is positively correlated with future product destruction. A fall in current product creation results in a lower number of products and therefore a lower degree of competition among surviving products in the future, leading to lower product destruction in the future. On the other hand, a current fall in product creation is negatively correlated with past product destruction. To understand this finding, consider that it is equivalent to the case with current product destruction that is correlated negatively with future product creation. An anticipated fall in product creation that results from weak expected economic condition in the future, reduces current production, leading to a high degree of product destruction in the present period. Thus, the negative correlation of current product creation with past product destruction is generated by the forward looking nature of investment dynamics related to the creation of new products. The insulation effect originated by a fall in current product creation retains a stronger effect on future product destruction than current product destruction and therefore recessions exercise strong insulation effects on future product destruction.

\section{Conclusion}

The analysis performed in this paper - with the help of a general equilibrium model that features endogenous product creation and destruction - shows that recessions destroy less efficient products on impact, allocating resources towards more efficient products. However, during the recovery phase while aggregate productivity recovers, this process is reversed, and less profitable products remain in the market. The analysis establishes that

\footnotetext{
${ }^{29}$ As shown in the right panel in Figure 6, the current correlation between product creation and product destruction may become positive for sufficiently low value of the persistence of the shock $(\rho)$. When the technological process is less persistent, the effect of the shock becomes intra-temporal and it is characterized by quick reversal. As explained in the previous section, since output and product creation are highly correlated, the insulation effect of creation on destruction is stronger for sufficiently low values of the persistence parameter of the technological process.
} 
recoveries are driven by a decrease in the rate of product destruction as opposed to an increase in product creation.

The analysis shows that endogenous product destruction is critical to evaluate the effect of permanent polices aimed to stimulate the economy. For instance, the effect of a permanent decrease in sunk entry costs on the profitability of the production line and the scale of production depends on whether product destruction is an additional margin of adjustment. In the presence of endogenous product destruction, a fall in sunk costs raises wages and simultaneously increases the level of plant-specific productivity required to maintain a production line's profitability, which in turn, decreases the marginal costs of production and therefore increases profits and the scale of production. Conversely, if product destruction is constant, a permanent fall in sunk costs leads to an increase in wages that raises marginal costs, therefore decreasing profits and the scale of production.

The theoretical model shows that the insulation effect is important and that a decline in current product creation sharply decreases future product destruction. We show that the correlation between product destruction and output may be positive or negative, depending on the degree of product heterogeneity and the persistence of the aggregate labor productivity shock. Therefore, the theoretical framework is able to accommodate contrasting empirical results.

The findings of the analysis outline important intertemporal tradeoffs for economic policies aimed at stimulating the economy. For instance, in the presence of endogenous product destruction, permanent entry deregulation stimulates the economy, but it fosters the survival of inefficient production units during the recovery phase. Similarly, subsidies to operational costs stimulate the economy but at the cost of a decrease in average productspecific productivity. These tradeoffs make the evaluation of economic policies complex and call for further investigation on the welfare implications of economic policies.

The analysis may be extended across several dimensions. First, by introducing nominal price rigidities, the model may be used to investigate the effect of demand-driven recessions and monetary policy shocks on product dynamics. Second, the theoretical framework may be extended to incorporate multi-product firms, as in Bernard et al. (2010) and Minniti 
and Turino (2013), which may shed light on the interplay between the fall in output and product destruction during recessions. Finally, another interesting extension is to consider vertical and horizontal differentiation in production varieties and to investigate interactions between changes in the quality and variety of products during recessions.

\section{References}

Aghion, P., Howitt, P., 1992. A Model of Growth through Creative Destruction. Econometrica $60,323-351$.

Bachmann, R., Bayer, C., 2013. Wait-and-see business cycles? Journal of Monetary Economics 60, $704-719$.

Berger, D., Vavra, J., 2015. Dynamics of the U.S. Price Distribution. NBER Working Papers 21732. National Bureau of Economic Research, Inc.

Bernard, A.B., Redding, S.J., Schott, P.K., 2010. Multiple-product firms and product switching. American Economic Review 100, 70-97.

Bilbiie, F.O., Ghironi, F., Melitz, M.J., 2012. Endogenous Entry, Product Variety, and Business Cycles. Journal of Political Economy 120, 304 - 345.

Blanchard, O., Giavazzi, F., 2003. Macroeconomic Effects of Regulation and Deregulation in Goods and Labor Markets. The Quarterly Journal of Economics 118, 879-907.

Bloom, N., Floetotto, M., Jaimovich, N., Saporta-Eksten, I., Terry, S.J., 2012. Really Uncertain Business Cycles. NBER Working Papers 18245. National Bureau of Economic Research, Inc.

Bonfiglioli, A., Crin, R., Gancia, G., 2016. Trade, Finance and Endogenous Firm Heterogeneity. CESifo Working Paper Series 5835. CESifo Group Munich.

Bonfiglioli, A., Crin, R., Gancia, G., 2017. Betting on Exports: Trade and Endogenous Heterogeneity. The Economic Journal, forthcoming. 
Broda, C., Weinstein, D.E., 2010. Product creation and destruction: Evidence and price implications. American Economic Review 100, 691-723.

Caballero, R.J., Hammour, M.L., 1994. The cleansing effect of recessions. American Economic Review 84, 1350-68.

Caballero, R.J., Hammour, M.L., 1996. On the timing and efficiency of creative destruction. The Quarterly Journal of Economics 111, 805-52.

Caballero, R.J., Hammour, M.L., 2005. The cost of recessions revisited: A reverseliquidationist view. Review of Economic Studies 72, 313-341.

Caballero, R.J., Hoshi, T., Kashyap, A.K., 2008. Zombie Lending and Depressed Restructuring in Japan. American Economic Review 98, 1943-77.

Cacciatore, M., 2014. International trade and macroeconomic dynamics with labor market frictions. Journal of International Economics 93, 17-30.

Cacciatore, M., Fiori, G., 2016. The Macroeconomic Effects of Goods and Labor Marlet Deregulation. Review of Economic Dynamics 20, 1-24.

Cacciatore, M., Fiori, G., Ghironi, F., 2015. The Domestic and International Effects of Euro Area Market Reforms. Mimeo. HEC Montreal, North Carolina State University and University of Washington.

Cacciatore, M., Fiori, G., Ghironi, F., 2016. Market deregulation and optimal monetary policy in a monetary union. Journal of International Economics 99, 120-137.

Campbell, J., 1998. Entry, exit, embodied technology, and business cycles. Review of Economic Dynamics 1, 371-408.

Caunedo, J., 2011. Industry dynamics, investment and uncertainty. Working Paper Cornell University , 278-317.

Chatterjee, S., Cooper, R., 2014. Entry And Exit, Product Variety, And The Business Cycle. Economic Inquiry 52, 1466-1484. 
Chugh, S.K., Ghironi, F., 2015. Optimal Fiscal Policy with Endogenous Product Variety. CEPR Discussion Papers 10674. C.E.P.R. Discussion Papers.

Clementi, G.L., Palazzo, B., 2016. Entry, Exit, Firm Dynamics, and Aggregate Fluctuations. American Economic Journal: Macroeconomics 8, 1-41.

Colciago, A., 2016. Endogenous market structures and optimal taxation. The Economic Journal 126, 1441-1483.

Davis, S.J., Faberman, R.J., Haltiwanger, J., 2006. The Flow Approach to Labor Markets: New Data Sources and Micro-Macro Links. Journal of Economic Perspectives 20, 3-26.

Felbermayr, G., Prat, J., 2011. Product market regulation, firm selection, and unemployment. Journal of the European Economic Association 9, 278-317.

Gabaix, X., 2011. The Granular Origins of Aggregate Fluctuations. Econometrica 79, $733-772$.

Ghironi, F., Melitz, M.J., 2005. International trade and macroeconomic dynamics with heterogeneous firms. The Quarterly Journal of Economics 120, 865-915.

Hamano, M., Zanetti, F., 2015. Endogenous Product Turnover and Macroeconomic Dynamic. Economics Series Working Papers 759. University of Oxford, Department of Economics.

Hamano, M., Zanetti, F., 2017. On Quality and Variety Bias in Aggregate Prices. Economics Series Working Papers 823. University of Oxford, Department of Economics.

Hopenhayn, H., Rogerson, R., 1993. Job turnover and policy evaluation: A general equilibrium analysis. Journal of Political Economy 101, 915-38.

Jaimovich, N., Floetotto, M., 2008. Firm dynamics, markup variations, and the business cycle. Journal of Monetary Economics 55, 1238-1252.

Kehrig, M., 2015. The Cyclicality of Productivity Dispersion. Working Papers. University of Texas at Austin. 
King, R.G., Rebelo, S.T., 1999. Resuscitating real business cycles, in: Taylor, J.B., Woodford, M. (Eds.), Handbook of Macroeconomics. Elsevier. volume 1 of Handbook of Macroeconomics. chapter 14, pp. 927-1007.

Lee, Y., Mukoyama, T., 2015. Entry and exit of manufacturing plants over the business cycle. European Economic Review 77, 20-27.

Lewis, V., 2013. Optimal Monetary Policy And Firm Entry. Macroeconomic Dynamics $17,1687-1710$.

Lewis, V., Poilly, C., 2012. Firm entry, markups and the monetary transmission mechanism. Journal of Monetary Economics 59, 670-685.

Melitz, M.J., 2003. The impact of trade on intra-industry reallocations and aggregate industry productivity. Econometrica 71, 1695-1725.

Minniti, A., Turino, F., 2013. Multi-product firms and business cycle dynamics. European Economic Review 57, 75-97.

Ottaviano, G.I.P., 2011. Firm Heterogeneity, Endogenous Entry, and the Business Cycle, in: NBER International Seminar on Macroeconomics 2011. National Bureau of Economic Research, Inc. NBER Chapters, pp. 57-86.

Poschke, M., 2014. The Firm Size Distribution across Countries and Skill-Biased Change in Entrepreneurial Technology. IZA Discussion Papers 7991. Institute for the Study of Labor (IZA).

Rossi, L., 2015. Endogenous Firms' Exit, Inefficient Banks and Business Cycle Dynamics. DEM Working Papers Series 099. University of Pavia, Department of Economics and Management.

Samaniego, R.M., 2008. Entry, exit and business cycles in a general equilibrium model. Review of Economic Dynamics 11, 529-541. 
Shao, E., Silos, P., 2013. Entry costs and labor market dynamics. European Economic Review 63, 243-255.

Vavra, J., 2014. Inflation Dynamics and Time-Varying Volatility: New Evidence and an Ss Interpretation. The Quarterly Journal of Economics 129, 215-258.

Zanetti, F., 2009. Effects of product and labor market regulation on macroeconomic outcomes. Journal of Macroeconomics 31, 320-332.

\section{A Steady State}

We start by deriving the steady state of the benchmark model. The Euler equation (18) provides:

$$
\frac{1}{\beta}=(1-\delta)\left(1+\frac{\widetilde{d}}{v}\right)
$$

Using the average profit equation (9), the ZCP equation (16), we can write equation (21) as:

$$
\frac{\widetilde{d}_{s}}{w}=\frac{\sigma-1}{\kappa-(\sigma-1)}
$$

From the definition of operational profits among products, we have $\widetilde{d}=S \widetilde{d}_{s} / N$, and the free entry condition (11) implies: $v=w$. Using these relations, we can express equation (21) as:

$$
\frac{1}{\beta}=(1-\delta)\left(1+\frac{S}{N} \frac{\sigma-1}{\kappa-(\sigma-1)} f\right),
$$

which provides the steady state endogenous destruction rate, $S / N$, given operational fixed costs, $f$.

We set the value of $\chi$ so that the steady state labor supply is equal to one. From the law of motion of products (12), we derive the number of new products, $H=\delta N /(1-\delta)$. Using these relations in the labor market clearing condition (19), it yields:

$$
\frac{1}{N}=(\sigma-1) \frac{S}{N} \frac{\sigma-1}{\kappa-(\sigma-1)} f+\sigma \frac{S}{N} f+\frac{\delta}{1-\delta}
$$


which provides a unique solution for the number of products, provided the endogenous destruction rate, $S / N$. Once the value $S$ is obtained, the steady state values of other variables is straightforward to derive.

In the model with exogenous product destruction, we assume that $f=0$, which implies $S / N=1, \widetilde{d}=\widetilde{d}_{s}$. Using these conditions on the Euler equation (18) yields:

$$
\frac{1}{\beta}=(1-\delta)\left(1+\frac{\tilde{d}_{s}}{v}\right)
$$

Inserting equation (25) into the free entry condition (11) and the law of motion of products (12), the labor market clearing condition (19) yields:

$$
\frac{1}{N}=(\sigma-1)\left[\frac{1}{\beta(1-\delta)}-1\right]+\frac{\delta}{1-\delta}
$$

which determines the value of all products, $N$. It is relatively easy to find the steady state value for other variables.

\section{B Business cycles moments}

Table 4 reports second moments of key variables for the U.S. data against those for the benchmark model and the model with exogenous destruction. U.S. Data comes from King and Rebelo (1999). The performance of the three models to reproduce the standard deviation of empirically-consistent measure of aggregate output $\left(Y_{R}\right)$, consumption $\left(C_{R}\right)$ and investment fluctuations $\left(I_{R}\right)$ is similar. Overall, the analysis shows that the theoretical model replicates relatively well movements in output, consumption and investment in the data. 


\begin{tabular}{l|l|llll}
\multicolumn{2}{|l}{ Table 4: Second moments } & $Y_{R}$ & $C_{R}$ & $I_{R}$ & $L$ \\
\hline St. dev. (\%) & U.S. data & 1.81 & 1.35 & 5.30 & 1.79 \\
& Benchmark & 1.06 & 0.82 & 5.69 & 0.24 \\
& Exogenous destruction & 1.18 & 0.85 & 5.57 & 0.25 \\
\hline Relative st. dev. to $Y_{R t}$ & U.S. data & 1.00 & 0.74 & 2.93 & 0.93 \\
& Benchmark & 1.00 & 0.78 & 5.38 & 0.22 \\
& Exogenous destruction & 1.00 & 0.72 & 4.72 & 0.21 \\
\hline $\operatorname{Corr}\left(Y_{R t}, X_{t}\right)$ & U.S. data & 1.00 & 0.88 & 0.80 & 0.88 \\
& Benchmark & 1.00 & 0.97 & 0.85 & 0.79 \\
& Exogenous destruction & 1.00 & 0.99 & 0.82 & 0.75 \\
\hline
\end{tabular}

